RESEARCH AND PRACTICE

\title{
Evaluation of food access and food security concerns among public housing residents
}

\author{
Cheryl L. R. Gaddis DrPH, MPH, CHES, ${ }^{1}$ Brad Lian, PhD, ${ }^{2}$ Nicole Watts, MPH, ${ }^{1}$ and Leontyne Thompson, $\mathrm{MPH}^{1}$ \\ ${ }^{1}$ Department of Public Health, College of Health Professions, Mercer University, Atlanta, GA; ${ }^{2}$ Department of Community Medicine, Mercer \\ University School of Medicine, Macon, GA
}

\begin{abstract}
Background: In 2012, food insecurity affected $14.5 \%$ of the households in the U.S and $20 \%$ in the state of Georgia. Individuals who are food-insecure can experience malnutrition, and social and physical problems. The purpose of this study was to assess food access and security concerns in two counties of the North Central Health District 5-2 (NCHD 5-2) in Georgia and to aid in devising interventions to increase food access and reduce food insecurity.
\end{abstract}

Methods: Data collection involved surveying 399 public housing residents within two NCHD 5-2 counties using the Household Food Security Survey developed by the US Department of Agriculture. The survey contained 24 questions focusing on demographics and household food status and on the severity and prevalence of food access and security.

Results: Of the 399 participants, 91.9\% reported annual household incomes less than $\$ 30,000 ; 61 \%$ ( $\mathrm{n}=244)$ reported receiving Supplemental Nutrition Assistance Program (SNAP/food stamps) benefits, 11\% (n = 46) received Women, Infants, and Children (WIC) benefits, and 3.3\% $(\mathrm{n}=13)$ received Temporary Assistance for Needy Families (TANF). Results for food security status (whether or not families have access to food at all times) showed that $7.3 \%(n=29)$ were classified as high food secure, $22.8 \%(n=91)$ as marginally food secure, $30.6 \%(n=122)$ as low food secure, and $39.3 \%(n=157)$ as very low food secure.

Conclusions: Most of the residents with some form of food insecurity received government food assistance, yet still identified as being unable to feed themselves or their families for the month. Recommendations to evaluate this problem include additional research and implementation of public health efforts to address food access and insecurity through policy changes and implementation of programs.

Keywords: food access, food insecurity, public housing residents, food policies

\section{INTRODUCTION}

Since 1995, the United States Department of Agriculture (USDA) has provided annual food security reports for each state. The reports are based on the USDA's Household Food Security Survey (HFSS), an 18-item survey used to classify households as either food secure, marginally food secure, low food secure, or very low food secure. Food-secure households have access by all members at all times to enough food for an active, healthy life (Coleman-Jensen, Nord, \& Singh, 2013). Marginally food secure households have evidence of food insecurity among household members and concerns about adequate food supply and management (Podolsky, 2010). The food intake of low food secure households is occasionally reduced, and members have experienced hunger at some point. Very low food secure households repeatedly suffer from severe reductions in food intake and hunger (Bickel, Nord, Price, Hamilton, \& Cook, 2000).

In 2012, the USDA reported that $14.5 \%$ of the households in the United States were food insecure (i.e., less than food secure) throughout the year, an increase of nearly $100 \%$ from the $7.5 \%$ reported in 1995 (Coleman-Jensen, Nord, \&
Singh, 2013). Georgia currently ranks sixth in the nation for households having low food security and tenth for households with very low food security, at $16.9 \%$ and $6.9 \%$, respectively, both of which are higher than the national averages (Food Research Action Center, 2013; ColemanJensen, Nord, \& Singh, 2013).

Poverty is often cited as the foundation of food insecurity (Haering \& Syed, 2009). Food security is largely dependent on individuals' socioeconomic status (SES) such as wealth, income, education, and housing conditions (Bickel et al., 2000). Therefore, the poor and unemployed are those most likely to have limited access to food and to fall into one of the food insecurity categories. Public housing residents often share some of these SES characteristics (i.e., poor, often unemployed, less educated), as do individuals who qualify for benefits from Supplemental Nutrition Assistance Program (SNAP) and the Women, Infant, and Children (WIC) program. For instance, criteria for residency in public housing often include a specific annual gross income according to household size, qualification as a senior citizen/disabled, and current US citizenship or eligible immigration status. Criteria for SNAP and WIC benefits are also income-based, with the applicant's income falling 
within $100 \%$ of the federal poverty guidelines and not exceeding 185\% (United States Department of Agriculture, 2015a, 2015b).

The increase in food insecurity warrants attention because food insecurity can undermine healthy or optimal development, and lead to malnutrition and social and physical problems. Focusing attention to food insecurity primarily at the national and state levels may obscure relevant sub-trends. Further, county-level data and data from specific populations, particularly underserved populations, are lacking.

The objective of this study was to assess food access and security concerns among public housing residents within Georgia's North Central Health District 5-2 (NCHD 5-2), specifically Houston and Bibb Counties, to aid in implementation of interventions. The assessment was conducted to address system, environmental, and/or policy efforts to reduce the impact of food insecurity as a contributing factor to health disparities among public housing residents.

\section{METHODS}

\section{North Central Health District}

The North Central Health District (NCHD, District 5-2), located in middle Georgia, is comprised of 13 counties with 525,486 residents (Georgia Department of Public Health, Office of Health Indicators for Planning, 2015). The district is predominantly rural, in that 10 counties (Crawford, Hancock, Jasper, Jones, Monroe, Peach, Putnam, Twiggs, Washington, and Wilkinson Counties) are classified as rural and only 3 counties (Baldwin, Bibb, and Houston Counties) as urban. The NCHD strives to help residents achieve optimal health and to prevent diseases, promote health, and protect communities against health threats.

\section{Houston County}

Houston County has a population of 149,111, which represents $27 \%$ of the population within NCHD 5-2 (U.S. Census Bureau: State and County QuickFacts, 2015). The incorporated cities within the county include Centerville, Warner Robins, and Perry, the county seat. In 2013, the unemployment rate in the county was $7.6 \%$, the poverty level was $15.2 \%$, and the median household income was $\$ 54,893$ (U.S. Census Bureau: State and County QuickFacts, 2015).

The Warner Robins Houston County Housing Authority (WRHCHA) is a public housing agency located within Houston County that provides housing for income-eligible families, the elderly, and persons with disabilities. The WRHCHA manages 426 units of public housing within the city of Warner Robins and 40 units under the Houston County Authority. Funding for managing these housing units for low-income residents is administered by the U. S. Department of Housing and Urban Development. Residents of the WRHCHA must (1) meet requirements related to annual gross income, (2) qualify as a senior citizen, a person with a disability, or as a family, and (3) have current U.S. citizenship or eligible immigration status (Warner Robins Houston County Housing Authority, 2014).

\section{Bibb County}

Bibb County has a population of 153,905 , representing $28 \%$ of the total population of the NCHD 5-2 (U.S. Census Bureau: State and County QuickFacts, 2015). The incorporated cities within the county include Payne, Lizella, Dry Branch, portions of Musella, and Macon, the county seat (Macon-Bibb County Board of Elections, personal communication, November 9, 2015). In 2013, the Bibb County unemployment rate was $6.6 \%$, the poverty level was $24.9 \%$, and the median household income was $\$ 37,550$ (U.S. Census Bureau: State and County QuickFacts, 2015).

The Macon Housing Authority (MHA) provides public housing in Bibb County for income-eligible families, the elderly, and persons with disabilities. It owns and manages 2,216 units that include sites for families, senior citizens, and mini neighborhoods (Macon Housing Authority, 2013). Residents of the MHA must meet at least one of the minimum requirements of being a senior citizen; a person with a disability; or, as a family, make under the income limit which varies according to household size, as well as have current U.S. citizen or eligible immigration status.

\section{Study Population}

Study participants were public housing residents of Bibb and Houston Counties. Researchers collaborated with the respective public housing authorities in each county to recruit participants through distribution of flyers. The MHA in Bibb County and the WRHCHA in Houston County assisted in recruitment by placing flyers in residents' mailboxes and in rental offices. The flyers contained a brief description of the study; eligibility requirements (public housing residents over the age of 18 years); and information regarding survey administration dates, times, and addresses. The surveys, administered in public housing community centers, took approximately 15 minutes to complete. Participants were paid $\$ 10$ each for their time. Of the residents, 399 participated in the survey, 200 from Bibb County and 199 from Houston County.

\section{Instrument}

The results are based on self-reported responses to the HFSS and six demographic items (zip code, race, gender, household income, household size, and age). The HFSS is a categorical food-security-status measure developed by the US Department of Agriculture to describe the food security situation of US households. The reliability and validity of the survey have been established across years and across major population subgroups and has been widely used (Bickel et al., 2000). The HFSS contains 18 items about food availability in the household over the previous year. The items range in severity from worrying about food availability to running out of food.

Ten items in the HFSS concern the situation for adults in the household [e.g., "(I/We) worried whether (my/our) food would run out before (I/we) got money to buy more" and "In the last 12 months, did you ever eat less than you felt you should because there wasn't enough money for food?”]. 
Eight items focus on the situation for children under the age of 18 years in the household [e.g., "(My/Our child was/The children were) not eating enough because (I/we) just couldn't afford enough food"]. Based on responses of the participants, households were classified as high food secure, marginally food secure, low food secure, or very low food secure, based on their responses. Classifications for adultonly households and those with children were based on the following scales:

Households with no child present:

- Raw score zero - High food security

- Raw score 1-2 - Marginal food security

- Raw score 3-5 - Low food security

- Raw score 6-10 - Very low food security

Households with one or more children:

- Raw score zero - High food security

- Raw score 1-2 - Marginal food security

- Raw score 3-7 - Low food security

- Raw score 8-18 - Very low food security
Households with high or marginal food security are considered as food secure by the Department of Agriculture. Those with low or very low food security are considered as food insecure.

\section{RESULTS}

Most of the participants in our sample were female (64\%, $\mathrm{n}=257$ ) and black (89.9\%, $\mathrm{n}=358)$; a variety of ages were represented (Table 1). Less than half $(41.2 \%, n=164)$ of the participants reported having children under the age of 18 years in the household. Of the participants, $91.9 \%(n=340)$, reported having annual household incomes of less than $\$ 30,000$; only $2.2 \%(\mathrm{n}=8)$ had incomes greater than $\$ 50,000$. With respect to governmental assistance, $61 \%(\mathrm{n}=$ $244)$ of the participants reported receiving SNAP, $11 \%$ ( $\mathrm{n}=$ 46) receiving WIC, and $3.3 \%(\mathrm{n}=13)$ receiving TANF; $8.3 \%$ of the participants reported receiving aid from two of those sources. Of the participants, 33.5\% $(n=133)$ reported receiving no aid from any of these programs.

\section{Table 1. Individual and Family Characteristics as a Percentage of the Sample}

\begin{tabular}{|c|c|}
\hline Characteristic & $\%(n)^{a}$ \\
\hline \multicolumn{2}{|l|}{ Gender } \\
\hline Male & $35.6 \%(142)$ \\
\hline Female & $64.4 \%(257)$ \\
\hline \multicolumn{2}{|l|}{ Race } \\
\hline Black & 89.9\% (358) \\
\hline White & $8.5 \%(34)$ \\
\hline Other & $1.5 \%(6)$ \\
\hline \multicolumn{2}{|l|}{ Age (in years) } \\
\hline $19-44$ & $45.1 \%(180)$ \\
\hline $45-64$ & $44.1 \%(176)$ \\
\hline 65 and over & $10.8 \%(43)$ \\
\hline \multicolumn{2}{|l|}{ Income } \\
\hline$\$ 0-\$ 29,999$ & $91.9 \%(340)$ \\
\hline$\$ 30,000-\$ 49,999$ & $5.9 \%(22)$ \\
\hline$\$ 50,000$ and over & $2.2 \%(8)$ \\
\hline \multicolumn{2}{|c|}{ Children (under age 18) in household } \\
\hline Yes & $41.2 \%(164)$ \\
\hline \multicolumn{2}{|l|}{ Government Assistance } \\
\hline SNAP & $61.0 \%(244)$ \\
\hline WIC & $11.0 \%(46)$ \\
\hline TANF & $3.3 \%(13)$ \\
\hline
\end{tabular}

Overall, $30.1 \%$ of the participants were classified as food secure and $69.9 \%$ as food insecure. Most $(75.4 \%, 91 / 120)$ who were classified as food secure were only marginally so. Of the participants, $7.3 \%(n=29)$ were classified as high food secure, $22.8 \%(\mathrm{n}=91)$ as marginally food secure, $30.6 \%(n=122)$ as low food secure, and $39.3 \%(n=157)$ as very low food secure. These results were similar by county $\left(\chi^{2}[2, \mathrm{~N}=399]=1.27, p=0.26\right)$ and by age, gender, and racial categories (all $p$ values $>0.05$ ).

With respect to the governmental assistance programs, $73.7 \%(199 / 266)$ of those receiving any form of assistance and $65.7 \%(23 / 35)$ of those reporting receiving assistance from 2 or more of the programs were classified as being 
food insecure. The percentages associated with food insecurity were $74.2 \%, 63 \%$, and $76.9 \%$ for SNAP, WIC, and TANF recipients, respectively. The prevalence of food insecurity for those not receiving any of those three forms of aid was $62.4 \%(83 / 133)$.

\section{DISCUSSION}

The findings show that food access and security are a major concern among public housing residents of Bibb and Houston Counties. Of the surveyed residents, 69.9\% were identified with some form of food insecurity. Most residents who reported receiving government food assistance were still identified as being unable to feed themselves and/or their families for the entire month, leaving them to go without food and/or rely on low-cost, and perhaps lowquality food for the remainder of the month. For instance, $72 \%$ of participants who received SNAP benefits were still considered food insecure. The recent decrease in SNAP benefits (Bolen, 2015) may have contributed to the inability of governmental assistance recipients to provide adequate amounts of food for themselves and their families. Additionally, the income requirements for government food assistance lead some to reason that federal food and nutrition assistance programs may overlook many people who should be considered eligible (Cook, 2002). Individuals who are food insecure can experience food deprivation, malnutrition, famine, and social and physical problems.

The fundamental cause of food insecurity and hunger in the United States is poverty, marked by a lack of resources to address basic needs such as food, shelter and health care (Haering \& Syed, 2009). Nevertheless, according to the present findings, federal and state programs intended to help the poor meet their basic needs are, in many instances, falling short. Poverty is a dominant contributor to food insecurity among the participants.

\section{Limitations}

The study has several limitations. Since the participants were recruited via flyers, this was essentially a convenience sample and may not represent the diversity (attitudinally or demographically) inherent in public housing developments. Thus, generalizing findings based on this convenience sample should be made cautiously. Moreover, the findings are based on self-reports, an oft-noted study limitation, because participants may interpret items and situations differently (e.g., hunger, balanced meal, worry), and different samples may produce different results (i.e., there may be reliability issues). Previous research on food insecurity, however, has also relied on self-reports (Bickel et al., 2000). Others should assess the topic in a more appropriate manner. Finally, the HFSS does not address the reasons for compromised food consumption (e.g., dieting or fasting) and so may over- or underestimate the degree of food insecurity and may lead to misguided policy prescriptions. This limitation presents as an opportunity for further studies to be conducted to identify specific reasons for compromised food consumption among these residents, particularly those who also receive some form of governmental food assistance. Further, the food security scale does not capture all possible dimensions of food insecurity. It also does not measure food safety, nutritional status, or the availability of food through "socially acceptable" channels, nor does it measure community-level factors such as the nature and sources of the available food supply (Bickel et al., 2000).

\section{CONCLUSIONS}

Hunger among American households due to insufficient resources is a continuing challenge. Implementation of food programs has eliminated many forms of extreme hunger, but less severe forms of food insecurity still exist. The present assessment identified the need to assess gaps within the resources, services, and systems pertaining to food access and food security. Out of the 399 residents surveyed, 69.9\% were categorized as having some form of food insecurity. Although many of the participants are recipients of the government assistance program SNAP, residents still identified as being unable to feed themselves and/or their families for the entire month, leaving them to go without food and/or to rely only on low-cost, and perhaps lowquality, food for the remainder of the month.

The results demonstrate that, as food access and security remain a problem at the national and state levels, it also exists at a lower level. Assessment of this issue on the county level would allow generalization of the results to the entire county for development of interventions at this levels. To be eliminated, food insecurity should be addressed at multiple levels.

\section{Implications for Public Health}

Of surveyed residents, 69.9\% were identified with some form of food insecurity. Most residents who receive government food assistance were still identified as being unable to feed themselves and/or their families for the entire month, leaving them to go without food or rely on low-cost, and perhaps low-quality food for the remainder of the month. Recommendations are that (a) further assessments should be conducted to evaluate this problem and (b) through research and development of effective policies and programs, public health efforts should be implemented within Bibb and Houston Counties to address the issue of food insecurity.

\section{Research Implications}

More research is recommended to determine specific reasons for food insecurity. For instance, more information on how people make their living and what resources they use to obtain food would establish if the amount of income is the main contributing factor. This can be derived through qualitative research, including conducting focus group discussions and key informant interviews to allow for more subjective responses. In future assessments of food security in Bibb and Houston Counties, facilitators should conduct research to establish the level of food insecurity, how long it has existed, and the causes. Observations, such as determining availability of grocery store may allow a comparison of qualitative data with previously collected quantitative data. 
Policy and Program Implications

The present results reveal the need for changes in policies related to food access, particularly those targeted towards people in poverty. Policies and programs implemented to improve community food security should address a range of issues, including participation in and access to federal food assistance programs, economic opportunity and job security, and ecologically sustainable agricultural practices and local food systems (Allen, 1999). Examples include promotion of the federal food assistance programs, community gardens, community-supported agriculture programs, farm-to-school initiatives, and food policy councils (Allen, 1999). At two of its sites, the WRHCHA has established community gardens and orchards (Sharon Rogers, personal communication, February 19, 2014). Initiatives such as these could be developed at additional public housing sites to aid in the distribution of healthy fruits and vegetables to the residents.

The food access and security assessments showed that 73.7 $\%$ of the participants who received government assistance were still food insecure. This shows that the food assistance programs do not ensure food security and that there is a need for improvement of these programs, and/or an increase in effective food promotion programs. One method of meeting that need is through acceptance of SNAP and WIC benefits at farmers' markets. Both farmers' markets in Bibb and Houston Counties accept these benefits indicating that more promotion of the benefits associated with these federal programs would be helpful. Food policy councils can prove to be beneficial in this regard, as this approach allows for representatives from different groups (federal food programs, public housing representatives, and local farmers) to examine the food system and provide recommendations for improvement (Story, Kaphingst, Robinson-O'Brien, \& Glanz, 2008).

\section{Acknowledgement}

This research was supported by funding from the North Central Health District 5-2 Health Promotions Program. The authors would like to thank the public housing residents for taking the time to participate in this study. We would also like to thank the Resident Housing Coordinators for their assistance in identifying locations and notifying the residents of our need for their participation in the study.

\section{References}

Allen, P. (1999). Reweaving the food security safety net: Mediating entitlement and entrepreneurship. Agriculture and Human Values, 16(2), 117-129.

Bickel, G., Nord, M., Price, C., Hamilton, W., \& Cook, J. (2000, March). Guide to measuring household food security, Revised 2000. Alexandria, VA: US Department of Agriculture, Food and Nutrition Service.

Bolen, Ed. (2015). Approximately 1 million unemployed childless adults will lose SNAP benefits in 2016 as state waivers expire. Washington, DC: Center on Budget and Policy Priorities.

Coleman-Jensen, A., Nord, M., \& Singh, A. (2013, September). Household food security in the United States 2012 (ERR-155). United States Department of Agriculture, Economic Research Service.

Cook, J.T. (2002). Clinical implications of household food security: Definitions, monitoring, and policy. Nutrition in Clinical Care, 5(4), 152-167.

Food Research Action Center. (2013). Prevalence of householdlevel food insecurity and very low food security by state 20102012 and 2007-2009. Retrieved from: http://frac.org/pdf/2013_09_04_usda_food_insecurity_bys tate_2010_2012.pdf

Georgia Department of Public Health, Office of Health Indicators for Planning (OHIP). (2014). Online Analytical Statistical Information System. Retrieved from https://oasis.state.ga.us/.

Haering, S.A., \& Syed, S.B. (2009). Community food security in the United States cities: A survey of the relevant scientific literature. Baltimore, MD: Johns Hopkins Center for a Livable Future.

Macon Housing Authority. (2013). Public housing. Retrieved from: http://maconhousing.com/publichousing.aspx

Podolsky, R. (2010). Hunger survey report. Retrieved from http://www.brhpc.org/files/Hunger_Survey_Report.pdf.

Story, M., Kahpingst, K.M., Robins-O’Brien, R., \& Glanz, K. (2008). Creating healthy food and eating environments: Policy an environmental approach. Annual Review of Public Health, 29, 253-272.

United States Census Bureau. (2015). State and county QuickFacts. Retrieved from http://quickfacts.census.gov/qfd/states/13/13021.html.

United States Department of Agriculture. (2015a). Supplemental Nutrition Assistance Program (SNAP). Retrieved from http://www.fns.usda.gov/snap/eligibility.

United States Department of Agriculture. (2015b). Women, Infants, and Children (WIC). Retrieved from http://www.fns.usda.gov/wic/wic-eligibility-requirements.

Warner Robins Houston County Housing Authority. (2014). Retrieved from: http://www.warnerrobinsha.com/index.php. 